\title{
Method for the removal of selected cells from cytological smear preparations for transmission electron microscopy
}

\author{
JEAN MATHER, CYNTHIA M STANBRIDGE, E BLANCHE BUTLER \\ From the Cytology Laboratory, St Mary's Hospital, Manchester M13 OJH
}

SUMMARY The method described depends on fixing additional cytology smear preparations with glutaraldehyde to be used, if needed. Removal of cells from the slide makes use of partially polymerised resins in the usual way but a paper marker is used to localise the area in the resin block which contains the cells to be examined. Slides are placed in a freezing cabinet to facilitate easy separation of the resin block.

In recent years transmission electron microscopy (TEM) has become a useful adjunct to morphological diagnosis in histopathology and cytopathology. Cytological specimens often contain relatively few key cells and this has stimulated interest in methods designed to remove selected cells from cytological smears. All methods are based on the use of partially polymerised resin to cover and surround selected cells so that after complete polymerisation the plane of cleavage is between the cells and the slide. ${ }^{1}$ Modifications of this basic technique have been introduced to ensure good preservation of material, accurate selection of cells and easy separation of the resin block from the slide. ${ }^{2-5}$ The method described in this paper is an attempt to simplify the procedure to make it viable for routine diagnostic use.

\section{Material and methods}

The method has been used for all types of cytological material and is routine when specimens of body cavity fluid are received. Two additional smears are made and fixed in $2.5 \%$ glutaraldehyde in $0.1 \mathrm{M}$ sodium cacodylate buffer ( $\mathrm{pH} 7 \cdot 4)$ for two to four hours. After fixation the smears are rinsed several times in cacodylate buffer before being stained by a modification of the Papanicolaou method. The smears are mounted using Polymount and a coverslip and examined by light microscopy. Single cells or cell groups to be removed are recorded by photography and are marked on the underside of the slide using a diamond marker with the selected cells in the centre of the circle. The coverslip is removed using xylene and the smear is rehydrated through alcohols before destaining with $1 \%$ acid alcohol. Following this, smears are washed in distilled water and cacodylate buffer and then postfixed in $1 \%$ osmium tetroxide for $30 \mathrm{~min}$. After dehydration through graded alcohols to $100 \%$ acetone the smear is impregnated with Taab epoxy resin as follows:

25:75 Taab epoxy resin: Acetone $30 \mathrm{~min}$
$50: 50$
$75: 25$
$100 \%$ resin
$30 \mathrm{~min}$

A modified wad punch (Figs. 1a, b) is used to make

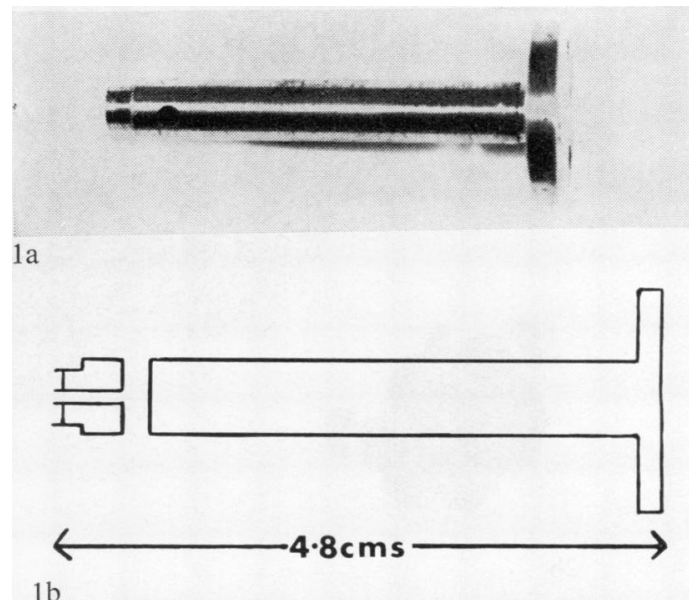

Fig. 1 (a) Modified wad punch. (b) Diagram to show the modification of the wad punch. 
paper markers which are the exact size of the gelatin capsule to be used (size 3 capsule, $5.5 \mathrm{~mm}$ diameter) with a hole $1 \mathrm{~mm}$ in diameter at the centre. A wad punch is a tool used for punching holes in paper, leather or any other soft material; it consists of a hollow metal tube with a sharpened end. The modification consists of tooling the sharpened end to punch out a paper marker of the required size and, in addition, make a hole $1 \mathrm{~mm}$ in diameter in the centre of the marker. Excess resin is removed and a drop of fresh resin placed over the marked area. The paper marker is then centred over the selected cells, this can be checked by light microscopy, and a size 3 gelatin capsule, filled with resin, is placed on top of the marker. Slide and capsule are left in an oven at $60^{\circ} \mathrm{C}$ overnight to polymerise; it has not been found necessary to support the capsule with a clamp. Following polymerisation, slide and capsule are placed in a freezing cabinet at $-20^{\circ} \mathrm{C}$ for a few minutes after which slide and capsule separate with- out difficulty. The part of the resin block which contains the selected cells is identified by the hole 1 $\mathrm{mm}$ in diameter in the centre of the paper marker and the rest of the resin can be trimmed away and a trapezium formed. Ultrathin sections are cut, stained and examined in the usual way.

It has to be remembered that the selected cells are very close to the surface of the block and sections must be cut with care. This difficulty can be overcome by double embedding but we have not found the procedure sufficiently worthwhile to justify the additional processing time required.

\section{Results}

An example of the technique is shown in Figs. $2 a$ and b. Fig. 2b (inset) is the photomicrograph of a fragment seen in a cytocentrifuge glutaraldehydefixed slide from the pleural fluid of a patient with diffuse mesothelioma. The same fragment is seen in

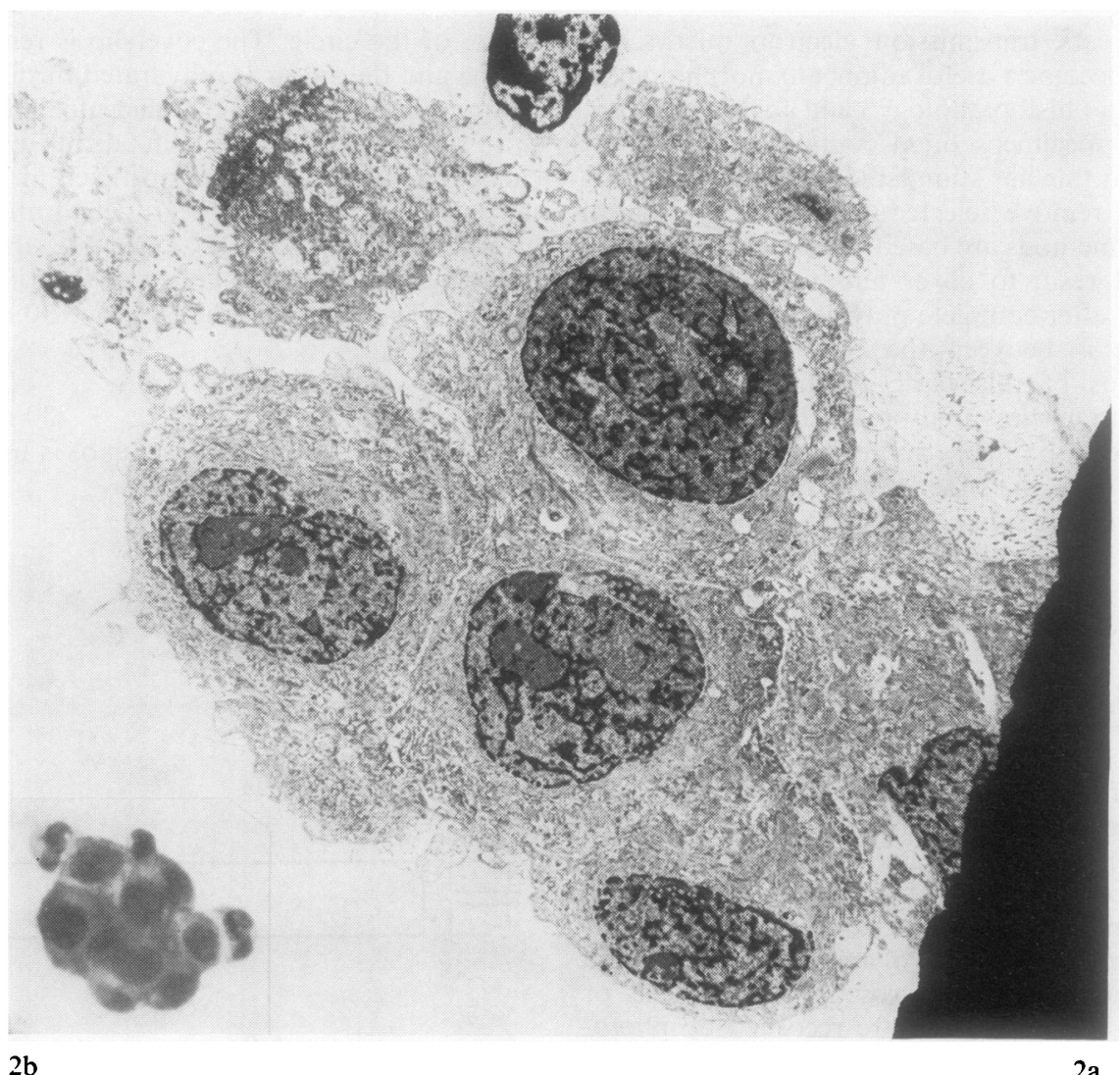

Fig. 2 (a) Electron micrograph of the group of cells shown inset (bottom left). Original magnification $\times 6250$. (b) Photomicrograph of cells to be removed from the slide. Papanicolaou stain. Magnification $\times 250($ enlarged $\times 4)$. 
Fig. 2a and can be orientated by the lymphocyte at 12 o'clock which is also seen in Fig. $2 b$. The quality of the electron micrograph demonstrates the value of the technique in diagnosis.

\section{Discussion}

The most important modification in this method is the use of a paper marker to localise the area in the resin block which contains the cells to be examined. Small areas can be identified using polyethylene embedding capsules but these need to be held in place with some form of clamp and we found difficulties in preventing air entering at the junction. This problem does not arise with gelatin capsules but these are larger in diameter and some method of localisation becomes necessary; the use of a paper marker has been a simple solution.

Various methods have been described to implement separation of the slide and capsule, ${ }^{1-5}$ in this method a freezing cabinet is used and these are readily available in most laboratories. The quality of the preparation depends on correct fixation in the first instance and this can only be achieved by anticipating that electron microscopy may contribute to the diagnosis when the specimen arrives in the laboratory.
This work was aided by Grant Number 975 from the Medical Research Council. It is a pleasure to thank Mrs LE Chawner for assistance with photography.

\section{References}

${ }^{1}$ Nebel BR, Minick OT. Embedding aid for coverslip mounts in electron microscopy. J Biophys Biochem Cytol 1956;2, suppl 4:61-3.

${ }^{2}$ Zidovsky J, Gaspar S. The method of selective detection of exfoliated vaginal cells in the electron microscope. Acta Cytol $1967 ; 11: 437-8$.

${ }^{3}$ Takeda M. Virus identification in cytologic and histologic material by electron microscopy. Acta Cytol 1969;13: 206-8.

4 Coleman DV, Russell WJI, Hodgson J, Tun Pe, Mowbray JF. Human papovavirus in Papanicolaou smears of urinary sediment detected by transmission electron microscopy. J Clin Pathol 1977;30:1015-20.

${ }^{5}$ Ruiter DJ, Mauw BJ, Beyer-Boon ME. Ultrastructure of normal epithelial cells in Papanicolaou-stained cervical smears: an application of a modified open-face embedding technique for transmission electron microscopy. Acta C.ytol 1979;23:507-15.

Requests for reprints to: Dr E Blanche Butler, Cytology Laboratory, St Mary's Hospital, Manchester M13 0JH, England. 